\title{
Variations in affinity to Candida albicans in vitro among human buccal epithelial cells
}

\author{
R. L. SANDIN*, A. L. ROGERS*†§, M. I. FERNANDEZ $\ddagger$ and E. S. BENEKE*† \\ Departments of "Botany and Plant Pathology, †Microbiology, $\ddagger$ Psychology-Methodology and $\S$ Medical \\ Technology Program, Michigan State University, East Lansing, Michigan 48824, USA
}

\begin{abstract}
Summary. Using an in-vitro adherence assay it was observed that the number of Candida albicans cells that attached to individual buccal mucosal cells varied greatly. Three mucosal-cell characteristics-state of aggregation, size and viability-that might influence yeast adhesion in vitro were studied. The number of attached yeast cells per mucosal cell varied from 0 to 32 . The majority of buccal cells $(88 \%)$ had none or very few yeasts attached, whereas a minority of cells $(12 \%)$ bound more than one half of all the attached yeasts. In donors whose buccal cells had large numbers of attached yeasts this percentage increased and the number of cells with no attached yeast cells fell. Cells of an intermediate size $(36-70 \mu \mathrm{m})$ had a greater affinity for yeasts than did cells of other sizes. Buccal cell viability appeared not to be necessary for adhesion of yeasts. No significant differences were observed in the number of yeast cells attached to single buccal cells compared with attachment to buccal cells within sheets. It would appear, therefore, that there are distinct subpopulations of epithelial cells with high and low affinity for attachment by $C$. albicans in vitro. Mucosal cell size or viability might influence this affinity.
\end{abstract}

\section{Introduction}

The adherence of micro-organisms to biological surfaces is considered to be an important first step in the process of colonisation and infection of mammalian membranes (Gibbons and Van Houte, 1975). Early studies focused on the bacterial moiety of the attachment process and recent work has addressed the attributes of mucosal cells that influence bacterial adhesion (Svanborg-Eden et al., 1977; Sklavounou and Germaine, 1980). For instance, epithelial cells have been shown to exhibit large cell to cell variations in the number of bacteria that adhere to their surfaces (Fowler and Stamey, 1977; Bartelt and Duncan, 1978; Rosenstein et al., 1985).

Studies on adhesion of Candida albicans have focused largely on the yeast cells or their growth environment, while little is known about the influence that the state of the mucosal cells might exert on yeast attachment; consequently, we looked to see whether mucosal cells exhibit uniform affinity to attachment by $C$. albicans. Buccal epithelial cells were chosen because they are a natural mucocutaneous surface for yeast attachment, as occurs in

Received 3 Nov. 1986; accepted 28 Nov. 1986. thrush (Rippon, 1982). Three mucosal cell traits that might influence yeast adhesion were examined. These were size, viability and state of aggregation.

\section{Materials and methods}

\section{Buccal mucosal cells}

Buccal mucosal cells were collected by gently rubbing the insides of the cheeks of 12 healthy adult volunteers ( 6 males, 6 females) with sterile swabs and then rotating the swabs in phosphate-buffered saline $(0.01 \mathrm{M}$ sodium phosphate dibasic in normal saline) (PBS) at $p \mathrm{H} \mathrm{7.2.} \mathrm{The}$ donors were 20-40 years old, were not suffering from signs or symptoms of oral thrush and were not taking antibiotics. The cells were washed three times in PBS and resuspended to concentrations of $2 \times 10^{5} \mathrm{cells} / \mathrm{ml}$ of PBS, as determined by counting in a haemocytometer chamber.

When examined by light microscopy none of the cells included in this study was colonised by yeasts. Selected samples of cells were submitted to trypan blue (TB) exclusion tests before the adherence assay to gauge the relative proportion of dead cells. Equal amounts of cell suspension and $0.02 \% \mathrm{~TB}$ (in acetic acid $3 \%$ in PBS $p \mathrm{H}$ $7 \cdot 2$ ) were mixed, incubated at $24^{\circ} \mathrm{C}$ for $10 \mathrm{~min}$, placed on slides and examined by light microscopy. Some $50-90 \%$ of buccal cells stained blue, showing that they were dead. 


\section{Yeast cells}

C. albicans MSU-1, a strain previously isolated from a patient with thrush, was grown on Sabouraud Dextrose Agar (BBL, Cockeysville, MD, USA) slants at room temperature for 4 days. A loopful of cells was transferred to $100 \mathrm{ml}$ of Trypticase Soy Broth (BBL) with glucose $4 \%$ and incubated at $37^{\circ} \mathrm{C}$ on a rotary shaker $(180 \mathrm{rpm})$ for $13 \mathrm{~h}$ to develop into the stationary phase. A sample was removed, washed three times in PBS, and resuspended in tissue culture medium M199 (Gibco, Grand Island, NY, USA) adjusted to $p H 7 \cdot 2$. The suspension was incubated for $1 \mathrm{~h}$ at $37^{\circ} \mathrm{C}$ for the development of germ tubes, washed three times and resuspended in formaldehyde $0.5 \%$ in PBS for $30 \mathrm{~min}$ at $4{ }^{\circ} \mathrm{C}$ to kill the yeast cells. The formalin was removed by washing in PBS. The cells were divided into multiple small samples and frozen. Before each experiment, one sample was thawed and resuspended at a concentration of $2 \times 10^{6}$ cells $/ \mathrm{ml}$ in PBS. Thus, the ratio of yeast:mucosal cells in all studies was 10:1.

The majority of yeast cells possessed germ tubes after the germination treatment. Germinated yeasts were used for these studies because they had been shown previously to adhere in larger numbers to epithelial cells than did non-germinated yeasts (Kimura and Pearsall, 1980; Sandin et al., 1982; Sobel et al., 1984). Furthermore, the yeast with germ tube constitutes the intermediate stage between the blastospore and the filamentous (hyphal) elements. This has clinical relevance because mycelial elements are invariably present in tissues where colonisation has progressed to frank infection (Rippon, 1982). Lastly, work in progress had shown that several growth media reported to produce blastospores actually yielded spores with minuscule germ tubes; these could be mistaken for non-germinated varieties by non-discriminating workers.

Formaldehyde treatment for $30 \mathrm{~min}$, or freezing, did not change yeast adherence significantly when compared with untreated controls. Others have also found that low concentrations of formalin such as those used in these studies do not significantly alter adhesion values (Lee and King, 1983). Stationary-phase cells were used in this study because they have been shown to adhere more readily than logarithmic phase cells (King et al., 1980). To maintain a constant and standard supply of yeasts throughout all the experiments, a single large batch of stationary phase, germinated $C$. albicans was prepared, treated with formalin and frozen.

\section{In-vitro adherence assay and cell-by-cell study}

Adherence of $C$. albicans was studied as described by Sandin et al. (1982). Briefly, 0 2-ml samples of mucosal and yeast cells were pipetted into $12 \times 75 \mathrm{~mm}$ tubes and incubated on a rotary shaker $(180 \mathrm{rpm})$ for $1 \mathrm{~h}$ at $37^{\circ} \mathrm{C}$. Three tubes were used for each control and for each experimental test. Polycarbonate $(12-\mu \mathrm{m}$ pore size) filters (Nucleopore Corp., Pleasanton, CA, USA) were used for collection of the mixtures from each tube. Cells were washed with approximately $100 \mathrm{ml}$ of PBS under continual agitation. This pore size allowed non-adherent yeasts to pass through while retaining those adhering to buccal cells. The filters were stained with crystal violet and the number of yeasts adhering to 200 buccal cells was determined by light microscopy at $430 \times$. Double-blind conditions were used.

The three filters from each of the 12 donors were used for a cell-by-cell study. Using similar light microscopy, 50 buccal cells on each filter from a total pool of 1800 buccal cells were chosen at random and evaluated. We determined the number of yeasts adhering to each buccal cell and the maximum diameter of each buccal cell; this was measured with an ocular micrometer calibrated with a stage micrometer. We also determined whether the buccal cells were found as single cells or as members of sheets of cells.

\section{Results}

Variations in size and yeast adherence among buccal cells

The size of buccal cells and the number of yeasts adhering to each buccal cell varied considerably. The average cell measured $60 \mu \mathrm{m}$, but cells as large as $150 \mu \mathrm{m}$ and as small as $15 \mu \mathrm{m}$ were found, though infrequently. The average number of yeast cells that adhered to each buccal cell was $2 \cdot 9$, but a small group of buccal cells had as many as 32 yeasts attached and many others had none.

\section{Non-normal distribution in yeast adherence among mucosal cells}

The data from the 1800 buccal cells were broken down into number of yeasts adhering per cell; the minimum was zero and the maximum 32 (figure).

Analysis of cell distribution was performed after separation of the pooled cell data into two groups: cell data from subjects with large adherence values in the adherence assay ( $>300$ yeasts $/ 200$ buccal cells) and cell data from subjects with low adherence values $(<300$ yeasts $/ 200$ buccal cells). In subjects with large adherence values there was a fall of $31 \%$ in the percentage of buccal cells to which no yeasts were attached; this figure was $51 \%$ in subjects with low adherence values.

\section{Subpopulations of buccal cells with high and low affinity for $C$. albicans}

It became apparent that subpopulations of buccal cells varied in their affinity for $C$. albicans. To test this hypothesis, the 1800 cells were segregated into two arbitrary sub-groups-those cells with $0-8$ 


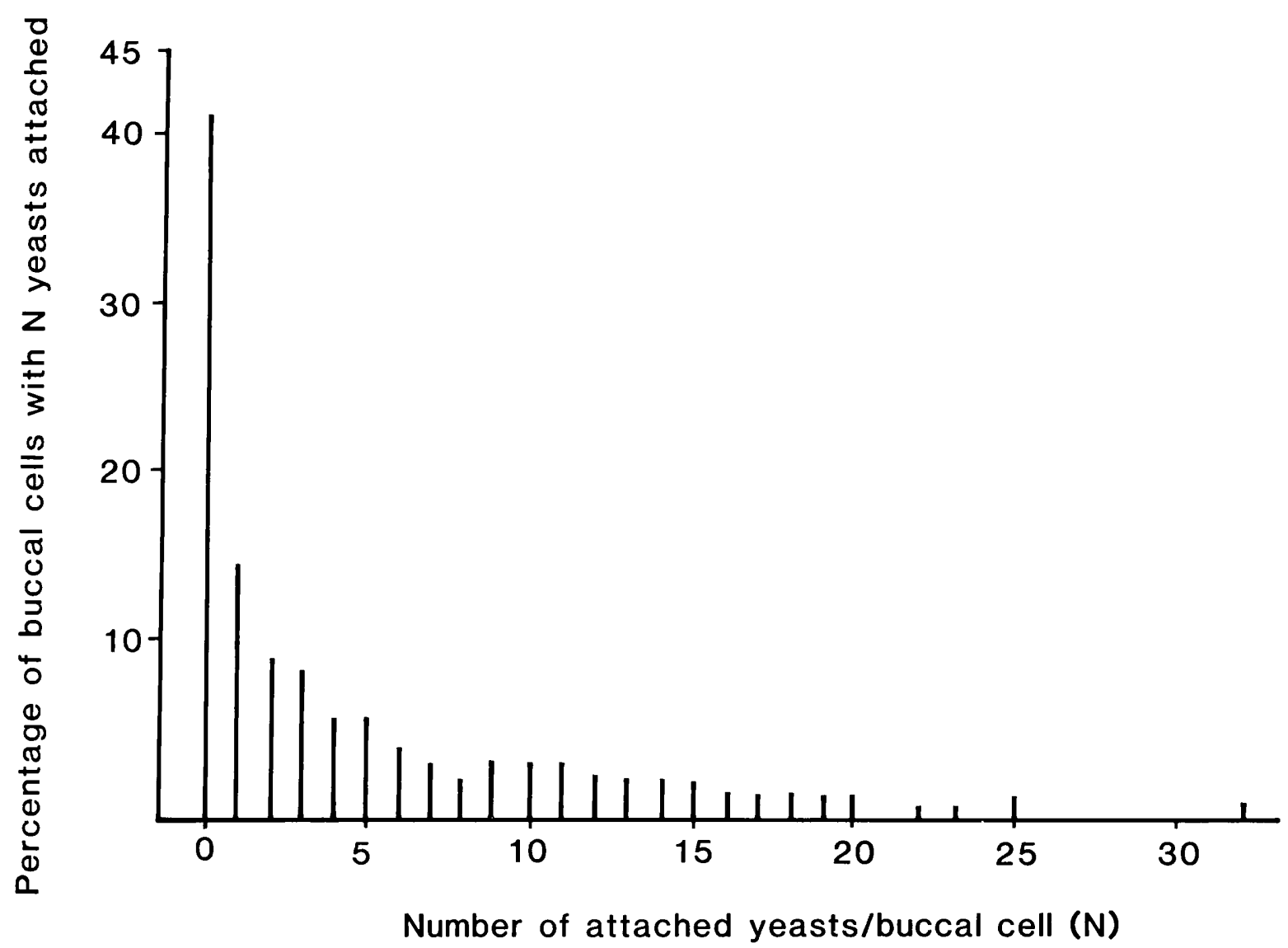

Figure. Distribution of 1800 buccal mucosal cells by number of adhering yeasts/cell.

attached yeasts/cell (group A) and those with 9 or more yeasts each (group B). Only $12 \%$ of cells had 9 or more yeasts attached, yet the number of yeasts (2542) attached to this small fraction of buccal cells (215) was more than one-half $(52 \%)$ of all the yeasts that adhered (4898). Thus, most of the yeasts were attached to a small group of highly receptive buccal cells. Results obtained with the cells from each of the 12 donors were similar to those obtained with the pooled data for cells from all donors.

\section{Influence of buccal cell size on yeast adherence}

To determine whether buccal cell size exerts an influence on yeast adherence, four arbitrary groups were established, based on cell size : $0-35 \mu \mathrm{m}, 36-$ $70 \mu \mathrm{m}, 71-105 \mu \mathrm{m}$ and $\geq 106 \mu \mathrm{m}$ (table). The majority of buccal cells $(73 \%)$ were in the $36-70 \mu \mathrm{m}$ interval, whereas $<4 \%$ were very large or very small cells. The average number of adherent yeasts/ buccal cell was calculated for each size interval.
Cells in the $36-70 \mu \mathrm{m}$ size range had the highest degree of adherence ( 3 yeasts/cell), whereas very large cells had the lowest $(2 \cdot 1$ yeasts/cell).

Table. Distribution of buccal cells into four groups based on size

\begin{tabular}{ccc}
\hline $\begin{array}{c}\text { Buccal } \\
\text { cell size } \\
(\mu \mathrm{m})\end{array}$ & $\begin{array}{c}\text { Percentage of buccal } \\
\text { cells in given size } \\
\text { group* }\end{array}$ & $\begin{array}{c}\text { Average number of } \\
\text { yeasts/buccal cell } \dagger\end{array}$ \\
\hline $0-35$ & $<3$ & $2 \cdot 7$ \\
$36-70$ & 73 & $3 \cdot 0$ \\
$71-105$ & 24 & $2 \cdot 7$ \\
$\geq 106$ & $<1$ & $2 \cdot 1$
\end{tabular}

* Number of buccal cells in size group/1800 buccal cells $\times 100$. The absolute values for each percentage figure were $(/ 1800): 49$, 1307,434 and 10.

† Total number of attached yeasts/total number of buccal cells in size group. The absolute values were, respectively: 134 yeasts/ 49 buccal cells, 3906/1307, 1177/434, 21/10. 


\section{Influence of buccal cell viability on yeast adherence}

To determine whether buccal cell viability exerts an influence on yeast adherence, a TB exclusion test was performed on selected adherence mixtures after the 1-h incubation assay. The stain was added to each system, followed by incubation for $10 \mathrm{~min}$ at room temperature. A loopful of cells was placed on slides and the number of yeasts attached to 50 randomly selected blue-stained buccal cells and to 50 non-stained cells was determined by microscopy. The majority of yeasts (1133 out of $1475,77 \%$ ) were attached to the surfaces of blue-stained epithelial cells, whereas $23 \%$ (342 out of 1475$)$ were attached to non-stained cells. Thus, buccal-cell viability appeared not to be necessary for candidal attachment.

Influence of using single buccal cells or cells in sheets for yeast adherence determinations

Early in the study it was observed that most buccal cells were found as single cells. However, many remained in sheets after swabbing the mucosa and were not dislodged. To determine whether this affected the results, randomly selected cells were reported as being either separate or in sheets, depending on their state of aggregation; $74 \%$ of cells ( 444 out of 600 ) were separated and $26 \%$ (156 out of 600 ) were within sheets. The average number of yeasts attached to each separate buccal cell was $2 \cdot 4$, whereas the average number attached to those in sheets was $2 \cdot 9$. This difference was not statistically significant (analysis of variance: $F$ value $2 \cdot 174 ; p<0 \cdot 141$ ). Thus, whether buccal cells occurred in sheets or as single cells did not appear to influence our results.

\section{Discussion}

Yeasts of the genus Candida commonly adhere to and colonise buccal mucosal cells (Odds, 1979). However, whether a differential affinity for $C$. albicans exists among these cells had not been examined. In the present study, buccal cells were examined individually to determine whether affinity for C. albicans varies between cells.

The numbers of yeasts attached to buccal cells was in the range 0 to 32 . A majority of cells $(41 \%)$ had no $C$. albicans attached, but a small number had many attached yeasts. A similar finding has been reported with streptococci (Bartelt and Dun- can, 1978) and Escherichia coli (Rosenstein et al., 1985). Thus, mucosal cells are distributed in a nonnormal fashion in terms of receptiveness to Candida. Numbers of cells that had no yeasts attached fell remarkably in subjects with large adherence values. To explain these findings, we considered the possibility that there might be subpopulations of cells with high and low receptivity for $C$. albicans. The finding that more than half of all attached yeasts adhered to $12 \%$ of buccal cells supports the hypothesis. However, this preliminary in-vitro work must be followed by in-vivo studies, i.e., in mucosal explants, to determine what role, if any, is played by high affinity mucosal cells in the causation of clinical oropharyngeal candidosis.

Factors that could contribute to the non-normal distribution in numbers of attached Candida cells included the indigenous bacterial microflora and the membrane receptor population on the mucosalcell surface. For instance, mucosal cells precoated with lactobacilli were shown to have decreased numbers of attached C. albicans (Sobel et al., 1981). Conversely, antibiotic treatment of hamsters decreased their intestinal bacterial microflora and promoted yeast adhesion, colonisation and dissemination from the gut (Kennedy and Volz, 1985).

The population of buccal cell receptors for $C$. albicans may vary from cell to cell. Environmental and host causes such as dietary and nutritional factors, or hormonal levels, could cause differences in the expression and number of receptors for Candida cells. Receptors on vaginal mucosal cells for streptococci and C. albicans are reported to vary with hormonal levels (Botta, 1981; Segal et al., 1984).

The size and viability of buccal cells may influence yeast adherence in vitro. Cells to which most yeasts attached were those in the size range 36-70 $\mu \mathrm{m}$. Thus, degree of receptiveness to $C$. albicans and amount of exposed surface area may not be equivalent. Dead buccal cells had more yeasts attached than live ones, in contrast to the situation with $E$. coli. Studies have shown that these organisms bind in greater numbers to live uroepithelial cells (Svanborg-Eden et al., 1977; Rosenstein et al., 1985).

Work in progress is aimed at the isolation and further characterisation of the subpopulations of highly receptive buccal mucosal cells, whose surface composition will be evaluated for the presence of molecules, e.g., fibronectin (Skerl et al., 1984), that could constitute the receptor(s) for $C$. albicans. 


\section{REFERENCES}

Bartelt M A, Duncan J L 1978 Adherence of group A streptococci to human epithelial cells. Infection and Immunity 20:200208.

Botta G A 1981 Possible role of hormones in the observed changes in adhesion of several microorganisms to epithelial cells from different body sites. FEMS Microbiology Letters $11: 69-72$.

Fowler J E, Stamey T A 1977 Studies of the introital colonization in women with recurrent urinary infections. VIII. The role of bacterial adherence. Journal of Urology 117:472-476.

Gibbons R J, Van Houte J 1975 Bacterial adherence in oral microbial ecology. Annual Review of Microbiology 29:1944.

Kennedy M J, Volz P A 1985 Ecology of Candida albicans gut colonization: inhibition of Candida adhesion, colonization and dissemination from the gastrointestinal tract by bacterial antagonism. Infection and Immunity 49:654-663.

Kimura L H, Pearsall N N 1980 Relationship between germination of Candida albicans and increased adherence to human buccal epithelial cells. Infection and Immunity 28:464-468.

King R D, Lee J C, Morris A L 1980 Adherence of Candida albicans and other Candida species to mucosal epithelial cells. Infection and Immunity 27: 667-674.

Lee J C, King R D 1983 Characterization of Candida albicans adherence to human vaginal epithelial cells in vitro. Infection and Immunity 41: 1024-1030.

Odds F C 1979 Candida and candidosis. Leicester University Press.

Rippon J W 1982 Candidosis and the pathogenic yeasts. In:
Rippon J W (ed) Medical mycology. The pathogenic fungi and the pathogenic actinomycetes, W B Saunders, Philadelphia, PA, pp 484-531.

Rosenstein I J, Grady D, Hamilton-Miller J M T, Brumfitt W 1985 Relationship between adhesion of Escherichia coli to uro-epithelial cells and the pathogenesis of urinary infection: problems in methodology and analysis. Journal of Medical Microbiology 20:335-344.

Sandin R L, Rogers A L, Patterson R J, Beneke E S 1982 Evidence for mannose-mediated adherence of Candida albicans to human buccal cells in vitro. Infection and Immunity 35: 79-85.

Segal E, Soroka A, Schechter A 1984 Correlative relationship between adherence of Candida albicans to human vaginal epithelial cells in vitro and candidal vaginitis. Sabouraudia 22: 191-200.

Skerl K G, Calderone R A, Segal E, Sreevalsan T, Scheld W M 1984 In vitro binding of Candida albicans yeast cells to human fibronectin. Canadian Journal of Microbiology 30: $221-227$.

Sklavounou A, Germaine G R 1980 Adherence of oral streptococci to keratinized and nonkeratinized human oral epithelial cells. Infection and Immunity 27:686-689.

Sobel J D, Muller G, Buckley H R 1984 Critical role of germ tube formation in the pathogenesis of candidal vaginitis. Infection and Immunity 44:576-580.

Sobel J D, Myers P G, Kaye D, Levison M E 1981 Adherence of Candida albicans to human vaginal and buccal epithelial cells. Journal of Infectious Diseases 143: 76-82.

Svanborg Eden C, Eriksson B, Hanson L A 1977 Adhesion of Escherichia coli to human uroepithelial cells in vitro. Infection and Immunity 18:767-774. 